\title{
TRANSICIÓN ECOLÓGICA Y EMERGENCIA CLIMÁTICA EN LAS ENSEÑANZAS DE TURISMO
}

\author{
Pilar Díaz-Cuevas* \\ Universidad de Sevilla \\ https://orcid.org/0000-0003-0846-9930 \\ Daniel Becerra-Fernández** \\ Universidad de Córdoba \\ https://orcid.org/0000-0002-6540-3631 \\ Arsenio Villar Lama* \\ Universidad de Sevilla \\ https://orcid.org/0000-0002-3840-4399
}

\section{RESUMEN}

Este trabajo valora la presencia de contenidos relacionados con la transición ecológica y la emergencia climática en los grados de Turismo andaluces. Para ello, se recopilaron los planes de estudio, programas y proyectos docentes de las materias impartidas y se analizaron las competencias y contenidos relacionados. Posteriormente se han extraído resultados globales y específicos (por universidades o departamentos). Los resultados muestran una limitada presencia de contenidos relacionados y la ausencia de conceptos emergentes sobre desafíos globales y nuevas pautas de desarrollo turístico.

Palabras clave: Cambio global; sostenibilización curricular; competencias; programas docentes; turismo.

\section{Ecological Transition and Climate Emergency on Tourism Education}

\section{ABSTRACT}

This paper evaluates the presence of contents related to the ecological transition and the climate emergency in the Tourism degrees in Andalusia. To this end, the curricula, programs

Fecha de recepción: 16 de abril de 2020.

Fecha de aceptación: 6 de julio de 2020.

* Departamento de Geografía Física y Análisis Geográfico Regional. Universidad de Sevilla. C/ María de Padilla, s/n. 41004 SEVILLA (España).E-mail: pilard@us.es, arsenio@us.es

** Departamento de Historia del Arte, Arqueología y Müsica. Universidad de Córdoba. Universidad de Córdoba 3, Pl. Cardenal Salazar, 14003 CÓRDOBA (España).E-mail: dbecerra@uco.es 
and teaching projects of the subjects were compiled and the competences and contents were analyzed. Finally, global and specific results (by universities or departments) have been obtained. The results show a limited presence of related contents and the absence of emerging concepts about global challenges and new patterns of tourism development.

Keywords: Global change; curricular sustainability; competences; teaching programs; tourism.

\section{INTRODUCCIÓN}

A la preocupación por los límites del crecimiento que viene manifestándose desde hace décadas (Meadows et al., 1972; Comisión Mundial del Medio Ambiente y del Desarrollo, 1992; entre otros), se une en los últimos años una inquietud por el posible colapso de las sociedades (Diamond, 2006), intensificado por los efectos del cambio global (Duarte, 2006), y más específicamente por uno de sus componentes: el cambio climático.

Desde los años 70 del siglo pasado, las movilizaciones y tomas de posición desde el ámbito social derivaron en la formulación de objetivos vinculados a la consecución de un desarrollo sostenible, y en el diseño de estrategias nacionales y supranacionales para alcanzarlo sucesivamente. En el caso de la comunidad científica, este proceso ha culminado con el surgimiento a finales del siglo XX de la llamada Ciencia de la Sostenibilidad (Vilches y Gil, 2015). Entre los objetivos actuales, destacan la definición de los diecisiete Objetivos de Desarrollo Sostenible (ODS) en 2015 por parte de Naciones Unidas(PNUD, 2015), o los Acuerdos de París (2016).

A pesar de todas estas estrategias, según queda recogido en el último informe de Naciones Unidas (ONU, 2019), la humanidad queda lejos de cumplir las metas fijadas para 2030 y 2050 en los distintos acuerdos internacionales sobre cambio climático, desarrollo sostenible y protección ambiental. Igualmente, el último informe de evaluación del Panel Intergubernamental del Cambio Climático (IPCC, 2018), constituye una llamada de los científicos para que los gestores asuman la gravedad de este problema y promuevan cambios drásticos en pos de una transición ecológica justa (García y Rodríguez, 2019).

Se incorpora de este modo, junto al concepto de emergencia planetaria aparecido hace décadas (Bybee, 1991), el concepto de emergencia climática, constituyendo éste, una medida adoptada como respuesta a esta situación. Diversos países y ciudades, junto con entidades y organizaciones nacionales y supranacionales, han declarado el estado de emergencia climática (Australia en 2016, redes de 7000 universidades en 2019, Unión Europea en 2019, entre otros).

En materia de educación, entre múltiples iniciativas destaca la llevada a cabo en 2005, cuando desde Naciones Unidas se impulsa un Programa de Acción Global, al que se adhirieron miles de docentes y centenares de instituciones educativas (Vilches y Gil, 2007). Igualmente, a nivel global el documento 'Learning for the future. Competences in Education for Sustainable Development' (ONU, 2012), formuló recomendaciones para 
todos los sectores de la educación y, también, determinó un marco de competencias básicas en materia de desarrollo sostenible para los educadores.

En el caso de la educación universitaria, la mayor parte de las propuestas llevadas a cabo, tanto nacionales como internacionales se dirigen a orientar el entrenamiento de competencias y contenidos básicos para la inclusión de la sostenibilidad en todas las titulaciones (Rychen y Salganik, 2003; Barth et al., 2007; Aznar, 2014; Lambrechts et al., 2017; Mindt y Rieckmann, 2017; Fariollyet al., 2017; Cebrián et al., 2020). Autores como Sterling (2005) argumentan que la sostenibilidad debe formar parte de la cultura universitaria y que toda la institución debe ser capaz de pensar en términos de sostenibilidad si no quiere contribuir a la insostenibilidad. No obstante el significado y el rigor del término sostenibilidad es objeto de debate en los últimos años (Aznar et al., 2011) y se proponen otros términos y paradigmas como núcleo del modelo didáctico.

Más recientemente, Ecologistas en Acción publicó el 'Manifiesto por una educación que afronte el estado de emergencia climática y planetaria' donde se identificaron ocho puntos, destacando la adaptación del currículum educativo a la necesaria transición a una sociedad ecológica y justa, el desarrollo de metodologías inclusivas que favorezcan el aprendizaje colectivo y la formación del profesorado para la emergencia climática y la transición ecológica y social.

En el caso del Sistema Universitario Español, como consecuencia de la adaptación al Espacio Europeo de Educación Superior, se ha experimentado un cambio en las metodologías docentes, que centralizan el proceso de aprendizaje del estudiante, en el enfoque de competencias (Real Decreto 1393/2007). Según éste, se asume que para resolver los problemas que la vida presenta es necesario contar con un saber interdisciplinar y experto, y no sólo con un cúmulo de conocimientos disciplinares, por sólidos que estos sean (Zúñiga et al., 2014; Díaz-Cuevas y Becerra-Fernández, 2020).

La complejidad de los retos a los que nos enfrentamos, hace que ninguno de ellos pueda ser resuelto aisladamente, siendo necesario formar ciudadanos y profesionales con capacidad de trabajo interdisciplinar (Garritz et al., 2014) y transdisciplinar. Se requiere del desarrollo de estrategias educativas diversificadas y procesos formativos de carácter transversalque fomenten la obtención por parte de los estudiantes, de un conocimiento en y para la acción y la resolción de problemas complejos (Díaz-Cuevas y Becerra-Fernández, 2020; Lawn, 2011).

En este sentido, la mayor parte de las experiencias llevadas a cabo en la Universidad española para la transición ecológica y la emergencia climática (TE y EC, en adelante) se vinculan a la implementación y promoción de la sostenibilidad, y a la realización de actuaciones para que ésta se integre de forma transversal en todos los títulos, convirtiéndose en un nuevo paradigma que impregne el conjunto de las disciplinas científicas y las actividades sociales (Garritz et al., 2014; Vilches y Gil, 2015; Albareda et al., 2017). A pesar de ello, son varios los autores que identifican grandes retos a superar en este sentido. Así por ejemplo, Aznar et al. (2011) constataron, como resultado de una encuesta a 331 profesores universitarios de la Universidad de Valencia, que la capacitación previa de estos en temas relacionados con la sostenibilidad era deficiente, que su universidad carecía de acciones de promoción y fomento de una cultura ambiental y de sostenibilidad y que la Universidad no incluía esos contenidos y competencias en sus diferentes asignaturas. 
Con carácter general, las competencias necesarias pueden agruparse en aquéllas que derivan de la racionalidad «teórica» "SABER", la racionalidad «práctica» "SABER HACER" y la racionalidad «ética» "SABER SER Y VALORAR” (Aznar y Ull, 2009).

En cuanto al SABER: La formación de nuevos y mejores profesionales en cualquier ámbito, capaces de afrontar los retos futuros, exige una buena comprensión por parte del alumnado de la situación actual mundial, causas y consecuencias. Pero especialmente importante resulta también el conocimiento de la existencia de modelos alternativos y de las prácticas y herramientas necesarias para responder a los problemas socio-ambientales y económicos actuales (Heras, 2016). Los conocimientos y las acciones educativas que deben llevarse a cabo han de estar fundamentadas en estudios científicos, principalmente en investigaciones realizadas desde las diferentes áreas del conocimiento que nos permitan lograr una correcta comprensión de la situación y concebir medidas adecuadas desde los diferentes ámbitos (Vilches y Gil, 2012: 32).

En cuanto al SABER HACER: Desde esta racionalidad, el trabajo que es preciso realizar se podría centrar en la contemplación de los problemas en su globalidad, pasando de un pensamiento cotidiano simplificador y fragmentario a un pensamiento más complejo y más adaptativo (García, 2004a; García, 2004b), basado en la incorporación de enfoques sistémicos, en la cooperación y en el trabajo transdisciplinar. De acuerdo con Garritz et al. (2014: 290) "Las estrategias concebidas han de responder a una perspectiva amplia, tanto espacial como temporalmente. Ello implica que la perspectiva sea espacialmente "glocal" (a la vez global y local) y que temporalmente contemple tanto el corto plazo como el medio y el largo, esforzándose en anticipar posibles riesgos y obstáculos, así como en aprovechar tendencias positivas".

Desde la racionalidad ética (SABER SER Y VALORAR), tal y como afirma García (2016, 156-157), "no basta con comprender las situaciones problemáticas, sino que es necesario intervenir en la posible gestión de las mismas e implicarse en su solución. Y esto, sin duda, exige educar para la participación, desde el compromiso colectivo, es decir, favorecer el análisis crítico, la toma de posición, el compromiso social y el trabajo solidario". Es necesario por tanto impulsar la responsabilidad social y la participación en los centros educativos y en nuestro entorno profesional y vital para poner en práctica algunas de las medidas y realizar el seguimiento de los resultados obtenidos (Murga-Menoyo y Novo, 2017).

Teniendo en cuenta la relación existente entre Cambio Climático y Turismo, ampliamente tratada (Smith, 1990; Gómez, 2005; da Cruz, 2009; Moreno, 2010; Olcina, 2012; Gómez, 2017; Olcina, 2018; Siddiqui e Imran, 2018), así como la interdisciplinaridad característica de esta titulación, en línea con la del sector, los grados de Turismo constituyen un laboratorio esencial para valorar el proceso de implantación de los contenidos y el desarrollo de las competencias necesarias. Y es que se trata de una titulación universitaria robusta y multidisciplinar, con marcado carácter empresarial pero de potentes atributos territoriales.

Este trabajo valora la presencia de contenidos relacionados con la transición ecológica y la emergencia climática en los grados de Turismo en Andalucía, a partir de un análisis de los planes de estudio, los programas y los proyectos docentes de todas las materias. Se analiza dicha presencia tanto en las competencias como en los temarios propuestos. 
Nos centraremos en el análisis de las competencias y contenidos vinculados a la racionalidad teórica o "SABER", por varios motivos. En primer lugar, porque un factor clave a considerar para cualquier propuesta educativa es ubicarla en un buen diagnóstico de la realidad que posibilite la respuesta a la situación de emergencia actual; en segundo lugar, porque la racionalidad práctica y ética no pueden desarrollarse sin una correcta y completa racionalidad teórica. Por último, porque en análisis amplios, valorar el entrenamiento y la adquisición por parte del alumnado de competencias y contenidos relacionados con la racionalidad práctica y ética, requiere de análisis más detallados -tanto cuantitativos como cualitativos- difíciles de llevar a cabo con el estudio de los planes de estudio.

\section{METODOLOGÍA Y FUENTES}

La metodología desarrollada para el alcance de los objetivos propuestos se ha basado en las siguientes fases:

En una primera fase se consultaron las páginas web de los grados de Turismo que se imparten en las universidades públicas andaluzas y se recopiló información de los planes de estudio relacionada con el número, tipo (formación básica, obligatoria u optativa) y el curso donde se imparten las diferentes asignaturas ofertadas.

En segundo lugar, se analizaron las competencias globales de cada uno de los grados -recogidas en el Libro Blanco de Grado en Turismo, en los acuerdos de la Comisión Andaluza del Título de Grado en Turismo y en acuerdos específicos de las propias universidades- con objeto de comprobar si existen grandes divergencias entre ellos. Al constatarse un alto nivel de similitud entre las titulaciones se entendió que las competencias globales se desarrollan adaptándose a los contenidos específicos de módulos y asignaturas.

En una tercera fase se recopilaron todos los programas y proyectos docentes, sistematizados en un total de 384 materias, excluyendo las asignaturas Trabajo Fin de Grado y Prácticas de Empresa.

En una cuarta fase el texto de estos programas docentes fue incorporado en una base de datos donde:

(i) En primer lugar se realizó un proceso de limpieza de texto, eliminando todo aquél texto (urls, signos de puntuación, números, caracteres sueltos, preposiciones, artículos, etc.), sin significado propio para el análisis.

(ii) Una vez eliminadas aquéllas palabras se analizó la frecuencia (número de veces) y lugar de aparición (parte del programa: objetivos, contenidos, temario, etc.) del resto de términos, prestando especial atención a aquéllos vinculados con la sostenibilidad, las nuevas pautas de desarrollo turístico. Para aquellas asignaturas donde no se encontró contenido de esta índole en el programa, se analizaron los proyectos docentes.

(iii) Posteriormente estos términos fueron agrupados según objetivo perseguido: comprensión y ética de la realidad actual (cambio climático, impactos ambientales, sociales, económicos, turistificación, masificación turística o sostenibilidad); alternativas o posibles soluciones encaminadas a la transición ecológica (destinos turísticos inteligentes, decrecimiento turístico, desturistización, slow tourism, casa 
vacaciones, turismo colaborativo, entre otros) y relacionadas con la capacidad práctica para la resolución (gestionar, aplicar, capacitar, etc.).

(iv) Finalmente, una vez realizadas las consultas (por competencias, contenidos, temario, palabras clave...) se han extraído resultados globales y específicos (por universidades o departamentos). Estos resultados han sido representadas mediante diversas infografías, gráficos de frecuencias y nubes de palabras (word clouds) y cartografías.

\section{RESULTADOS}

\subsection{Los Grados de Turismo en las universidades públicas andaluzas. Departamentos y materias ofertadas}

Según el Registro de Universidades, Centros y Títulos (RUCT), el Grado en Turismo se imparte actualmente en 47 centros universitarios españoles y en ocho de las diez universidades públicas andaluzas, cubriendo todas las provincias de la región: Universidades de Almería, Cádiz, Córdoba, Granada, Huelva, Jaén, Málaga y Sevilla (todas excepto la Universidad Pablo de Olavide y la Universidad Internacional de Andalucía). El Libro Blanco del Grado en Turismo (ANECA, 2004) establecía grandes bloques de materias de cara al diseño del título, en torno a los cuales cada universidad debía proponer las asignaturas que considerase más convenientes para desarrollarlos y concretarlos. Las titulaciones andaluzas -en la medida que se adaptan al Libro Blanco del Grado de Turismo- destacan por su carácter interdisciplinar y transversal. De hecho, en Andalucía, 103 departamentos diferentes imparten las 384 asignaturas ofertadas en estos grados. Este número varía desde 18 en las Universidades de Sevilla y Granada, a ocho en Huelva y Almería (figura 1).

\section{Figura 1 \\ NÚMERO DE DEPARTAMENTOS ENCARGADOS DE IMPARTIR DOCENCIA EN LOS GRADOS DE TURISMO ANDALUCES}

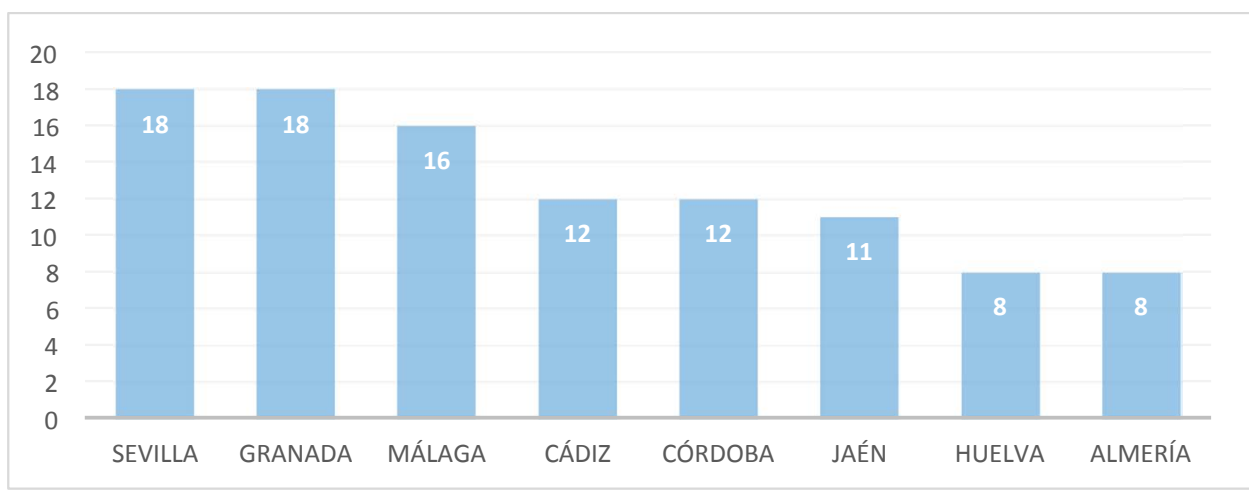

Fuente: Elaboración propia a partir de los Planes de Estudio de los grados de Turismo andaluces. 
Es necesario resaltar que un mayor número de departamentos no indica necesariamente la diversidad de los contenidos y puede relacionarse con la dimensión de las universidades analizadas y el número de departamentos de cada una de ellas. Las más pequeñas buscan la interdisciplinariedad entre un menor número de departamentos, confiando en que, internamente, habrá especialistas afines a las materias a impartir.

Atendiendo a la estructura general de estas titulaciones (figura 2), un 22,4\% de las asignaturas que se imparten se corresponden con Idiomas, mientras que las materias vinculadas con la Economía y la Empresa, incluyendo la Contabilidad, Finanzas y Marketing, concentran el 37,1\%. Los ámbitos de la Geografía y el Patrimonio aglutinan conjuntamente el 16,5\%, mientras que las asignaturas técnicas, relacionadas con Estadística e Informática suponen el $5,4 \%$. El $8,1 \%$ se vincula a asignaturas de Derecho y el 10,4\%se enlazan a una amplia variedad de materias, derivada de la gran cantidad de asignaturas optativas presentes en algunos grados, entre las que se encuentran Comunicación, Sociología y Psicología, entre otras.

\section{Figura 2 \\ ESTRUCTURA GENERAL POR MATERIAS (\%)}

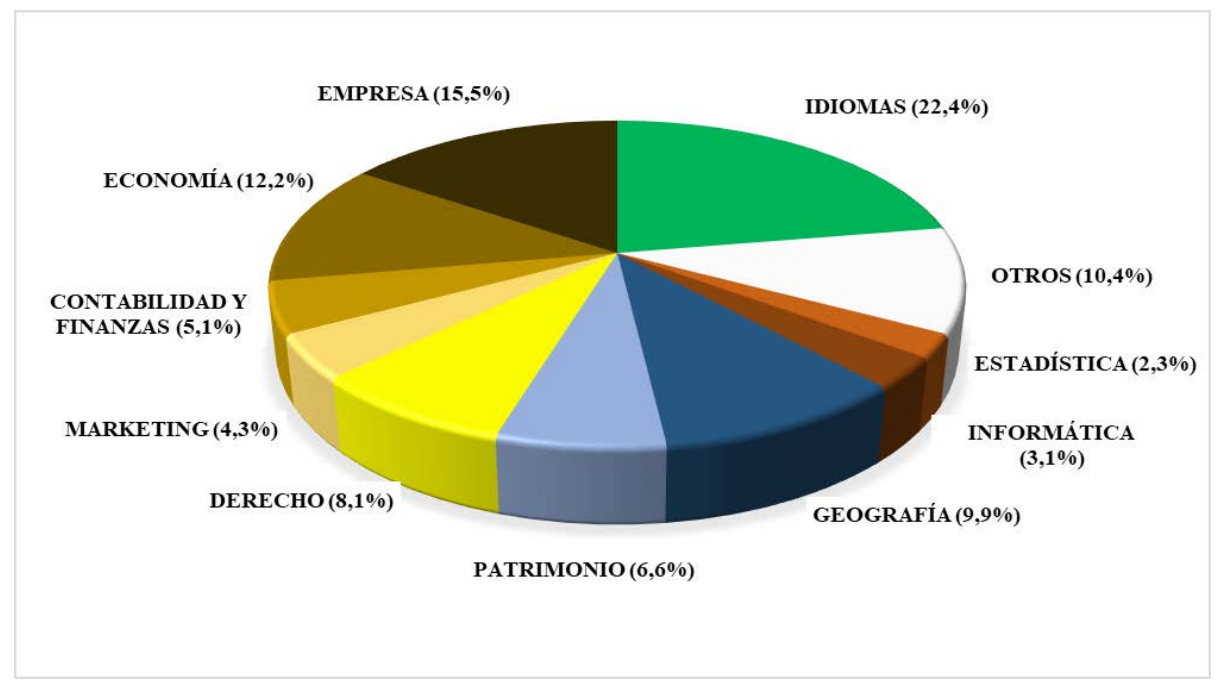

Fuente: Elaboración propia a partir de los Planes de Estudio de los Grados de Turismo andaluces.

Atendiendo al análisis específico de cada grado (figura 3), independientemente del tipo de asignatura ofertada (obligatoria, básica u optativa), los Idiomas, seguidos de Empresa y Economía, poseen una mayor presencia en todos los grados y concentran más de la mitad de las asignaturas ofertadas en los planes de estudio de las universidades de Huelva $(58,2 \%)$, Almería $(55,1 \%)$ y Jaén $(53,5 \%)$. 


\section{Figura 3 \\ MATERIAS OFERTADAS POR GRADO}

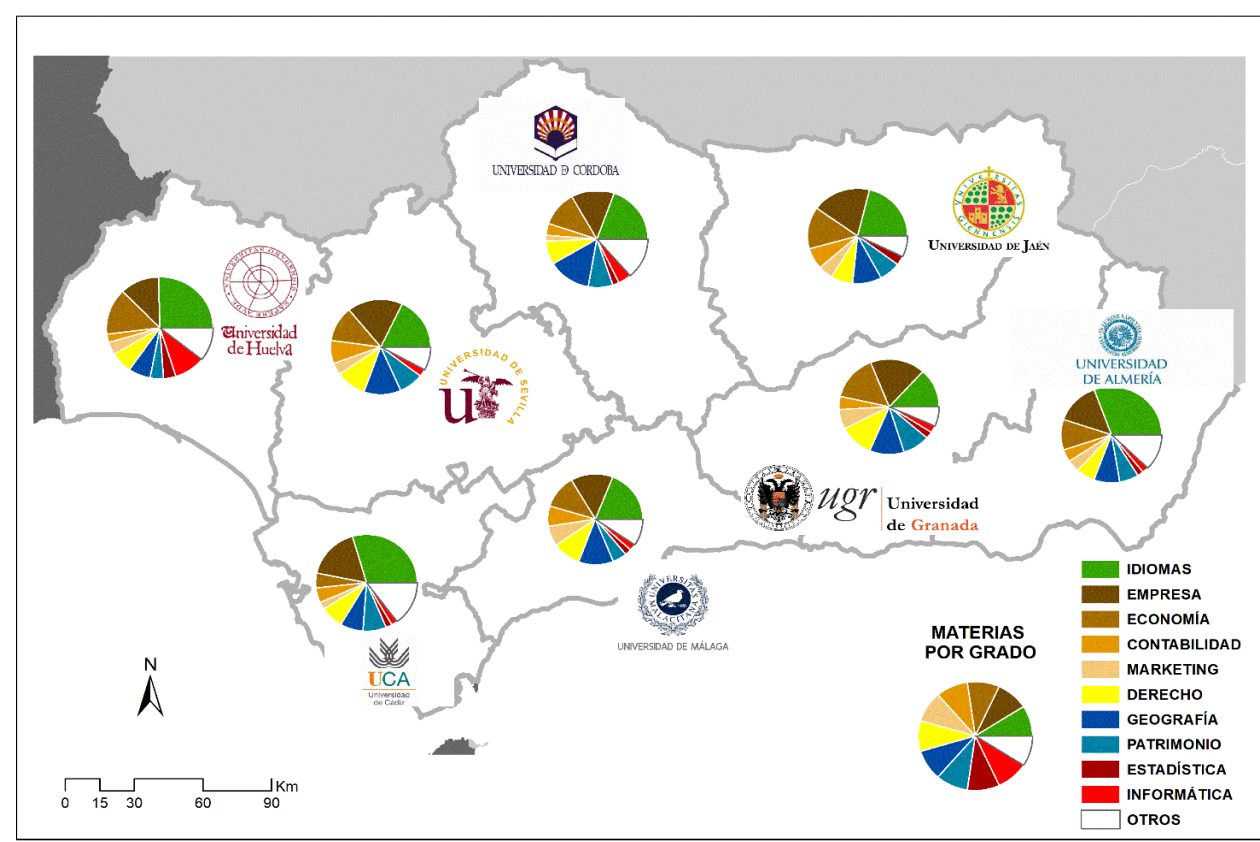

Fuente: Elaboración propia a partir de los Planes de Estudio.

Tras las anteriores, la Geografía es la que concentra un mayor número de asignaturas en todos los grados, siendo especialmente relevante su presencia en los grados de Sevilla $(11,8 \%)$, Granada (10,9\%) y Málaga (10,6\%). Tras Geografía, el Derecho y el Patrimonio se hacen presentes, destacando su importancia, en los grados de Granada, Sevilla, Córdoba y Cádiz.

\subsection{Competencias para la transición ecológica y la emergencia climática: Planes de Estudios}

Antes de analizar competencias y contenidos "a escala de asignatura", es necesario comprobar el tratamiento que se da a los conceptos clave en las memorias consolidadas de las titulaciones. Los Planes de Estudio contemplan las competencias generales y específicas del conjunto del Grado, competencias que van adaptándose a los módulos y materias, y que se analizarán en un tercer punto.

El Libro Blanco de Turismo y los acuerdos de la Comisión Andaluza para este Grado conducen a una gran semejanza entre las titulaciones que, no obstante, poseen cierto margen de maniobra para definir competencias acordadas en el seno de cada institución y/o cada centro. Las siguientes consideraciones son por tanto extensibles al conjunto del espacio universitario andaluz en el campo del turismo: 
- Los contenidos relacionados con la transición ecológica y la emergencia climática tienen una escasa presencia en las memorias de los grados de turismo andaluces.

- La única competencia directamente relacionada con este tema es la de Gestionar el territorio turístico de acuerdo con los principios de la sostenibilidad, presente en todos los casos, y la sensibilidad hacia temas ambientales, en tres de ellos. Resulta llamativo la no introducción de la sostenibilidad en la esfera empresarial, excepto en el caso de Granada, que es más integrador: Capacidad de desarrollar una adecuada gestión empresarial, territorial y patrimonial, que permita el aprovechamiento turístico de los recursos naturales y culturales, y de otra naturaleza, de acuerdo con los principios de sostenibilidad económica, social y medioambiental.

- Otras competencias afines tienen que ver con analizar los impactos del turismo (5 casos), conocer la responsabilidad social de las actuaciones de las empresas (4), el reconocimiento de la diversidad (3) y desarrollar una actitud globalizadora (1). Llama la atención que una de las claves actuales en la educación ambiental, la de pensar globalmente, sólo sea reconocida por una institución, en este caso la Universidad de Huelva: Desarrollar una actitud globalizadora que permita relacionar hechos de diversa índole así como comprender la multicausalidad de las realidades territoriales.

- No existe una correlación entre el análisis a nivel de grado y de asignaturas, de tal manera que los títulos que muestran una mayor sensibilidad medioambiental en sus memorias no tienen una correspondencia directa con el número de materias que reconocen tales contenidos.

\subsection{Competencias y contenidos para la transición ecológica y la emergencia climá- tica: Asignaturas y proyectos docentes.}

Excluyendo el Trabajo Fin de Grado y las Prácticas de Empresa, un total de 384 asignaturas se imparten en los grados de Turismo de las universidades públicas andaluzas (cuadro 1). La distribución de estas asignaturas por grados es desigual y el número de ellas varía desde las 38 asignaturas en la Universidad de Cádiz, a las 69 ofertadas por la Universidad de Huelva.

Con carácter general, 97 de estas asignaturas, el 25\% del total, recogen en sus programas o en alguno de sus proyectos docentes, competencias, contenidos temáticos u objetivos relacionados con la transición ecológica y/o emergencia climática. En el análisis por grados, destaca sobre los demás el Grado de Turismo de la Universidad de Granada, donde el $50 \%$ de las asignaturas que se imparten recogen contenidos relacionados, seguido por los grados de Cádiz y Córdoba (con un 37\%). Por su parte, los grados de Huelva, Málaga y Almería son los que poseen un menor porcentaje de asignaturas que incorporan contenidos de este tipo, con un 16\% (universidades de Huelva y de Málaga) y 11\% (Universidad de Almería). 


\section{Cuadro 1 \\ NÚMERO DE ASIGNATURAS POR GRADO QUE RECOGEN CONTENIDOS RELACIONADOS CON LA TRANSICIÓN ECOLÓGICA Y LA EMERGENCIA CLIMÁTICA}

\begin{tabular}{|l|c|c|c|}
\hline \multicolumn{1}{|c|}{ Grado de Turismo } & N $^{\text {o de asignaturas totales }}$ & $\begin{array}{c}\mathbf{N}^{\circ} \text { de asignaturas con } \\
\text { contenidos en TE y EC }\end{array}$ & $\begin{array}{c}\text { Porcentaje } \\
(\%)\end{array}$ \\
\hline Universidad de Granada & 44 & 22 & 50 \\
\hline Universidad de Cádiz & 38 & 14 & 37 \\
\hline Universidad de Córdoba & 52 & 19 & 37 \\
\hline Universidad de Sevilla & 49 & 11 & 22 \\
\hline Universidad de Jaén & 41 & 8 & 20 \\
\hline Universidad de Huelva & 69 & 11 & 16 \\
\hline Universidad de Málaga & 45 & 7 & 16 \\
\hline Universidad de Almería & 46 & 5 & 11 \\
\hline TOTAL & $\mathbf{3 8 4}$ & $\mathbf{9 7}$ & $\mathbf{2 5}$ \\
\hline
\end{tabular}

* Se excluyen las prácticas de empresa y los TFG.

Fuente: Elaboración propia a partir de los programas y proyectos docentes disponibles en las páginas web de los respectivos grados para el curso 2019-2020.

Esta desigual situación podría explicarse por la mayor o menor presencia de unas asignaturas u otras: Idiomas, Empresa, Geografía (figuras 2 y 3). Por ejemplo, en el caso de los Idiomas, podría pensarse que la incorporación de estos contenidos resulta difícil, al centrarse en las habilidades lingüísticas y comunicativas. Así, Almería y Huelva poseen muchas materias en Idiomas y escasos contenidos relacionados, y Granada presenta el mismo patrón en un sentido inverso. Sin embargo, no puede establecerse una relación directa: Cádiz, presentando muchas asignaturas de Idiomas, es la que posee un mayor peso de contenidos relacionados, tras Granada.

Atendiendo al tipo, la mayor parte de las asignaturas que recogen contenidos vinculados a la transición ecológica y la emergencia climática son de formación básica u obligatoria (en adelante FB u O), y por tanto deben ser cursadas y superadas por todo el alumnado para obtener el título (cuadro 2).

Vuelve a destacar sobre los demás el Grado en Turismo de la Universidad de Granada, donde, de las 22 asignaturas ofertadas con las características señaladas, 19 son obligatorias y de formación básica. Igualmente reseñable es el caso de Málaga, que con siete asignaturas de las características mencionadas, todas son obligatorias o de formación básica. Por su parte, la Universidad de Almería incorpora los contenidos planteados en sólo cinco asignaturas, de las cuales tres, se corresponden con asignaturas optativas.

Como ya se ha comentado, la inclusión de contenidos de TE y EC en el espacio universitario andaluz (Grado en Turismo) es muy limitada. De las 97 materias que recogen contenidos relacionados, 42 hacen una mera alusión en las competencias; mientras que 32, además de citarlas en ese epígrafe, los recogen en el temario. Otras asignaturas los 
mencionan en otras partes del programa sin citarlos en las competencias: 18 lo hacen en el temario y cinco en objetivos o resultados esperados. Este último hecho podría deberse, en primer lugar, a la pervivencia de una "cultura del temario" frente a la reciente "cultura de las competencias", según la cual el profesorado presta una mayor atención a los contenidos que explica respecto a las competencias que entrena. En segundo lugar, los temarios suelen ofrecer una mayor flexibilidad para el cambio y su desarrollo en epígrafes, especialmente en los proyectos docentes que se editan cada curso académico.

\section{Cuadro 2 \\ TIPO DE ASIGNATURAS POR GRADO QUE RECOGEN CONTENIDOS RELACIONADOS CON LA TRANSICIÓN ECOLÓGICA Y LA EMERGENCIA CLIMÁTICA}

\begin{tabular}{|c|c|c|c|}
\hline Grado de Turismo & $\begin{array}{l}\mathrm{N}^{\mathrm{o}} \text { de asignaturas con } \\
\text { contenidos en TE y EC }\end{array}$ & $\begin{array}{c}\text { De asignaturas de } \\
\text { FB u O }\end{array}$ & $\begin{array}{c}\text { De asignaturas } \\
\text { optativas }\end{array}$ \\
\hline Universidad de Granada & 22 & 19 & 3 \\
\hline Universidad de Córdoba & 19 & 14 & 5 \\
\hline Universidad de Cádiz & 14 & 10 & 4 \\
\hline Universidad de Huelva & 11 & 6 & 5 \\
\hline Universidad de Sevilla & 11 & 6 & 5 \\
\hline Universidad de Jaén & 8 & 6 & 2 \\
\hline Universidad de Málaga & 7 & 7 & \\
\hline Universidad de Almería & 5 & 2 & 3 \\
\hline TOTAL & 97 & 70 & 27 \\
\hline
\end{tabular}

Fuente: Elaboración propia a partir de los programas y proyectos docentes disponibles en las páginas web de los respectivos grados para el curso 2019-2020.

Si observamos las disparidades entre universidades (figura 4) se constata la idea anterior; y es que seis de los ocho grados presentan, en mayor o menor medida, asignaturas donde los contenidos relacionados sólo aparecen en las competencias.

El Grado en Turismo de Córdoba registra un mayor número de asignaturas de este tipo, de manera que, de 19 materias, 12 presentan contenidos en las competencias sin desarrollarlos en el temario. Esta situación es similar en el Grado de Turismo de Granada (9 de 22). En sentido inverso y proporcionalmente, es en Málaga donde hay una mayor preocupación por incorporarlos al temario, a veces directamente, sin tratarlos en las competencias; mientras que los casos de Jaén, Huelva, Sevilla y Cádiz, presentan situaciones intermedias. Finalmente, tres de los ocho grados presentan asignaturas donde la mayor parte de los contenidos no se localizan ni en las competencias ni en el temario, sino en otros puntos del programa (introducción, objetivos, resultados esperados...). Destaca en este sentido el caso de Almería. 


\section{Figura 4 \\ ASIGNATURAS POR GRADO QUE RECOGEN CONTENIDOS RELACIONA- DOS CON LA TRANSICIÓN ECOLÓGICA Y LA EMERGENCIA CLIMÁTICA}

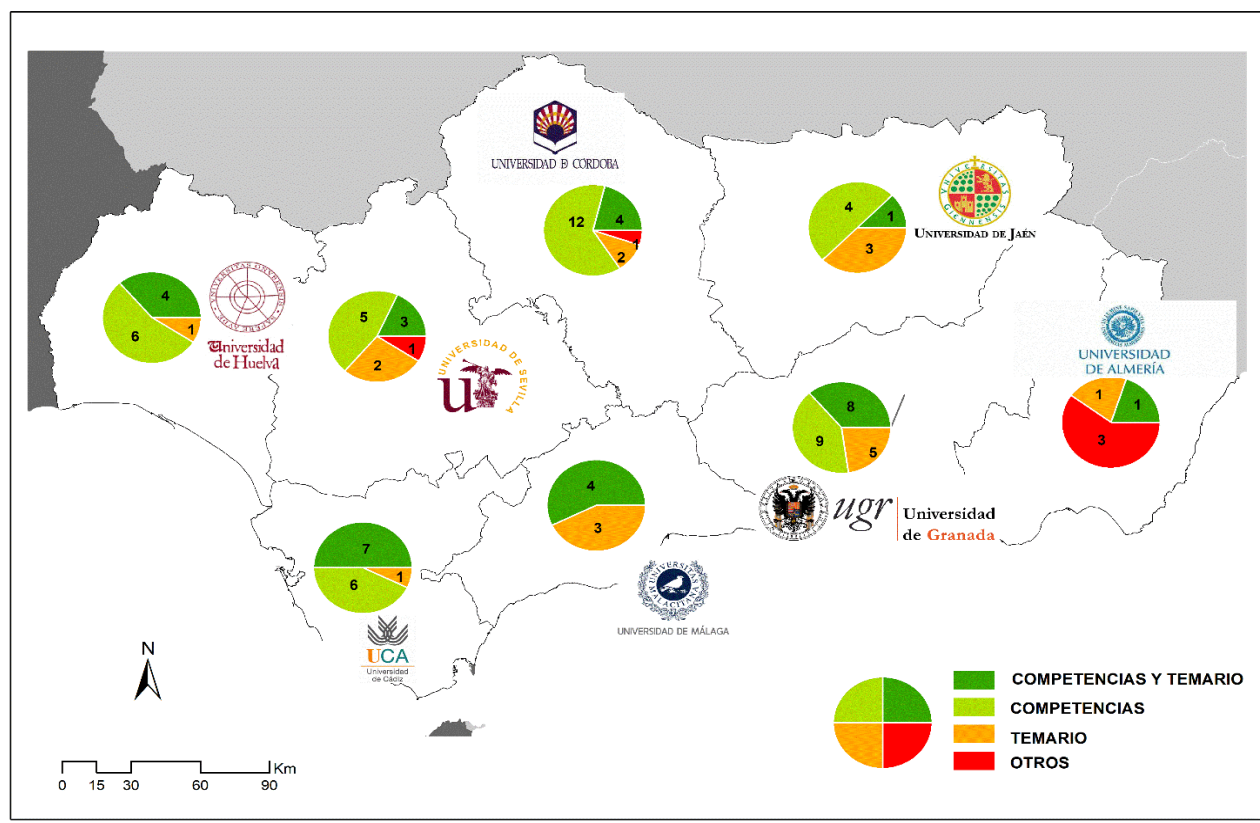

Fuente: Elaboración propia a partir de los programas y proyectos docentes disponibles en las páginas web de los respectivos grados para el curso 2019-2020.

Llegados a este punto cabe preguntarse en qué departamentos recae la impartición de los contenidos en TE y EC. En total son 45, esto es, casi la mitad (43\%) de los 103 departamentos implicados en la docencia de Turismo (cuadro 3). Esta cifra varía en función de cada grado: Mientras que en Granada la mayoría (11) aporta este tipo de contenidos (a través de los programas de alguna de sus materias), en Jaén y Almería esta tarea recae en tan solo dos departamentos.

\section{Cuadro 3 \\ DEPARTAMENTOS POR GRADO QUE RECOGEN CONTENIDOS RELACIONADOS CON LA TRANSICIÓN ECOLÓGICAY LA EMERGENCIA CLIMÁticA}

\begin{tabular}{|c|c|c|c|}
\hline Grado en Turismo & $\begin{array}{c}\mathrm{N}^{\mathrm{o}} \text { de } \\
\text { departamentos }\end{array}$ & $\begin{array}{c}\mathrm{N}^{\mathrm{o}} \text { de departamentos } \\
\text { que imparten contenidos } \\
\text { relacionados }\end{array}$ & Porcentaje (\%) \\
\hline Universidad de Granada & 18 & 11 & 72 \\
\hline Universidad de Sevilla & 18 & 8 & 44 \\
\hline
\end{tabular}




\begin{tabular}{|c|c|c|c|}
\hline Grado en Turismo & $\begin{array}{c}\mathrm{N}^{\mathrm{o}} \text { de } \\
\text { departamentos }\end{array}$ & $\begin{array}{l}\mathrm{N}^{\mathrm{o}} \text { de departamentos } \\
\text { que imparten contenidos } \\
\text { relacionados }\end{array}$ & Porcentaje (\%) \\
\hline Universidad de Málaga & 16 & 5 & 31 \\
\hline Universidad de Cádiz & 12 & 7 & 58 \\
\hline Universidad de Córdoba & 12 & 6 & 50 \\
\hline Universidad de Jaén & 11 & 2 & 18 \\
\hline Universidad de Almería & 8 & 2 & 25 \\
\hline Universidad de Huelva & 8 & 4 & 50 \\
\hline TOTAL & 103 & 45 & 43 \\
\hline
\end{tabular}

Fuente: Elaboración propia a partir de los programas y proyectos docentes disponibles en las páginas web de los respectivos grados para el curso 2019-2020.

A priori podría pensarse en una centralización de los contenidos en ámbitos como la Geografía, Historia, Antropología, Sociología y Humanidades. Estos departamentos son los encargados de impartir 47 de las 97 asignaturas que recogen contenidos en TE y EC. Posteriormente destacan los departamentos de Economía, que imparten 20 asignaturas de este tipo. No obstante, aunque estos departamentos tienen una posición destacada, existe una significativa diversidad (cuadro 4).

En algunos centros la impartición de estos contenidos está muy concentrada en unos pocos departamentos; son los casos de Huelva, Jaén o Almería. Aquí, a los departamentos vinculados a la Geografía se unen otros como Empresa y Marketing (Huelva), Economía (Jaén) o Psicología (Almería). En el lado opuesto se sitúan los grados cuyos contenidos en TE y EC se distribuye entre un mayor número de ámbitos disciplinares, como Granada, Sevilla o Cádiz.

\section{Cuadro 4 \\ DEPARTAMENTOS POR GRADO QUE IMPARTEN CONTENIDOS RELACIONADOS}

\begin{tabular}{|c|l|c|c|}
\hline Grado en Turismo & \multicolumn{1}{|c|}{ Departamento } & $\mathrm{N}^{\mathrm{o}}$ & C y T \\
\hline & Economía Aplicada & 3 & 2 \\
\hline & Economía Financiera y Contabilidad & 3 & \\
\hline & Economía Internacional y de España & 3 & 1 \\
\hline Granada & Geografía Humana, Filosofía y Letras & 3 & 3 \\
\hline & Geografía Física y Análisis Geográfico Regional & 2 & 1 \\
\hline & Comercialización e Investigación de Mercados & 2 & \\
\hline & Historia del Arte & 2 & \\
\hline & Prehistoria y Arqueología & 1 & 1 \\
\hline & Sociología & 1 & \\
\hline & Lenguajes Informáticos & 1 & \\
\hline & Derecho Internacional y Privado & 1 & \\
\hline
\end{tabular}




\begin{tabular}{|c|c|c|c|}
\hline Grado en Turismo & Departamento & $\mathrm{N}^{\mathrm{o}}$ & $\mathrm{CyT}$ \\
\hline \multirow{8}{*}{ Sevilla } & Geografía Física y Análisis Geográfico Regional & 3 & 1 \\
\hline & Administración de Empresas y Marketing & 2 & \\
\hline & Sociología & 1 & 1 \\
\hline & Economía Financiera y Dirección de Operaciones & 1 & \\
\hline & Derecho Administrativo & 1 & \\
\hline & Antropología Social & 1 & \\
\hline & Geografía Humana & 1 & \\
\hline & Historia del Arte & 1 & \\
\hline \multirow{2}{*}{ Jaén } & Antropología, Geografía e Historia & 4 & 1 \\
\hline & Economía & 4 & \\
\hline \multirow{2}{*}{ Almería } & Geografía, Historia y Humanidades & 4 & 1 \\
\hline & Psicología & 1 & \\
\hline \multirow{7}{*}{ Cádiz } & Historia, Geografía y Filosofía & 4 & 2 \\
\hline & Economía General & 3 & 2 \\
\hline & Organización de Empresas & 3 & 1 \\
\hline & Derecho del Trabajo y de la Seguridad Social & 1 & 1 \\
\hline & Economía Financiera y Contabilidad & 1 & \\
\hline & Marketing y Comunicación & 1 & 1 \\
\hline & Derecho Internacional Público, Procesal y penal & 1 & \\
\hline \multirow{6}{*}{ Córdoba } & $\begin{array}{l}\text { Departamento de Estadística, Econometría, } \\
\text { Investigación Operativa, Organización de } \\
\text { Empresas y Economía Aplicada }\end{array}$ & 7 & 2 \\
\hline & Geografía y Ciencias del Territorio & 6 & 2 \\
\hline & Derecho Público y Económico & 2 & \\
\hline & Ciencias Sociales y Humanidades & 2 & \\
\hline & Química Inorgánica e Ingeniería Química & 1 & \\
\hline & Historia del Arte, Arqueología y Música & 1 & \\
\hline \multirow{4}{*}{ Huelva } & Dirección de Empresas y Marketing & 3 & 1 \\
\hline & Historia, Geografía y Antropología & 5 & 3 \\
\hline & Economía & 2 & \\
\hline & Derecho Público & 1 & \\
\hline \multirow{5}{*}{ Málaga } & Geografía & 3 & 2 \\
\hline & $\begin{array}{l}\text { Psicología Social, Trabajo Social, Antropología } \\
\text { Social y Estudios de Asia Oriental }\end{array}$ & 1 & 1 \\
\hline & Historia del Arte & 1 & \\
\hline & Economía Aplicada & 1 & 1 \\
\hline & Derecho Público & 1 & \\
\hline
\end{tabular}

Nota aclaratoria: Se señala el número total de materias con contenidos relacionados (N), así como el no de ellas que desarrollan contenidos tanto en las competencias como en el temario $(\mathrm{C} \mathrm{y} \mathrm{T})$.

Fuente: Elaboración propia a partir de los programas y proyectos docentes disponibles en las páginas web de los respectivos grados para el curso 2019-2020. 


\subsection{Competencias y contenidos para la transición ecológica y la emergencia climá- tica: Análisis de palabras clave}

Hasta ahora se ha analizado la presencia de competencias entrenadas o temáticas impartidas relacionadas con la transición ecológica y la emergencia climática pero no se han especificado en qué contenidos se basa. En los siguientes párrafos se muestran los resultados derivados del análisis de las palabras clave y los conceptos utilizados en las 97 materias identificadas. Así, un total de 128 conceptos clave han sido recopilados y representados en una nube de palabras (figura 5).

\section{Figura 5}

\section{NUBE DE PALABRAS DERIVADA DEL ANÁLISIS DE PROYECTOS Y PROGRAMAS DE LAS ASIGNATURAS}

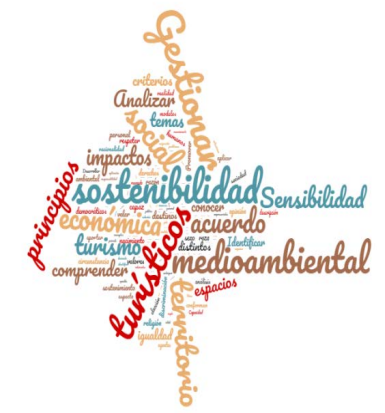

Fuente: Elaboración propia.

Al margen de la palabra turismo y sus derivados (turístico, turista...), el concepto sostenibilidad es el más repetido entre los programas y proyectos docentes. Exactamente se emplea en 43 ocasiones. No sorprende que los contenidos de la TE y EC se basen en un concepto anterior, ya muy asentado en la comunidad científica, como es el de desarrollo sostenible. También aparecen constantemente en estos proyectos y programas los términos vinculados a cada uno de los pilares de la sostenibilidad (ambiental, social y económico), lo que podría interpretarse como la adquisición de competencias "interdisciplinarias", necesarias para la acción. Si bien el término medioambiental y sus derivados se repiten 48 veces, el término económico lo hace en 31 ocasiones y el término social 33. Ello podría interpretarse como un entendimiento parcial de la sostenibilidad, identificándola con la parte ambiental, cuando este constituye un concepto integrador que pretende conseguir un equilibrio entre los factores económicos, ecológicos y sociales (Colom, 2000).

Igualmente interesante es la alta frecuencia del término territorio (33), que se asocia a la actividad de los departamentos de Geografía, que, siendo el hombre y su interacción con el espacio su objeto de estudio, y preocupados por los desafíos globales del planeta, se encargan de impartir gran parte de las asignaturas con contenidos relacionados.

Por otra parte deben subrayarse los verbos que "protagonizan" las competencias de estas materias. Entre ellos destaca gestionar con 41 menciones. También aparecen térmi- 
nos como promover (6), aplicar (4) y desarrollar (4), con los cuales podría interpretarse como la definición y entrenamiento de unas competencias vinculadas al conocimiento para la acción, que superaría la mera acción del conocimiento. No obstante, son los verbos vinculados al estricto conocimiento los que más repeticiones poseen: analizar (27), comprender (24), conocer (17) e identificar (13).

Otras palabras se relacionan con el entrenamiento de las competencias de racionalidad ética. Destacan entre ellas principios (30), acuerdo (29), igualdad (15) democráticos, derecho, discriminación, respetar, valores y velar (con 7 repeticiones cada una). En definitiva, es mayor la presencia de competencias y contenidos centrados en la racionalidad ética (intención) que en la acción.

De todo lo anterior se desprende la total ausencia de conceptos emergentes relacionados con las nuevas pautas de desarrollo y de comprensión de los fenómenos globales: transición ecológica, cambio climático, emergencia climática, decrecimiento, resiliencia, Objetivos 2030, Educación para el Desarrollo Sostenible, Educación para la Ciudadanía Global, etc. Y más concretamente términos paralelos en la literatura específica tales como turistización, masificación, slowtourism, turismo colaborativo.... Y es que la presencia de todos estos conceptos no es pequeña, es nula.

Un análisis detallado por los diversos títulos diferencia entre los que basan sus contenidos en un menor número de conceptos y aquellos que utilizan un amplio elenco de términos (figura 6).

\section{Figura 6}

NUBES DE PALABRAS POR GRADO DERIVADAS DE LAS COMPETENCIAS DE LOS PROYECTOS Y PROGRAMAS DE LAS ASIGNATURAS
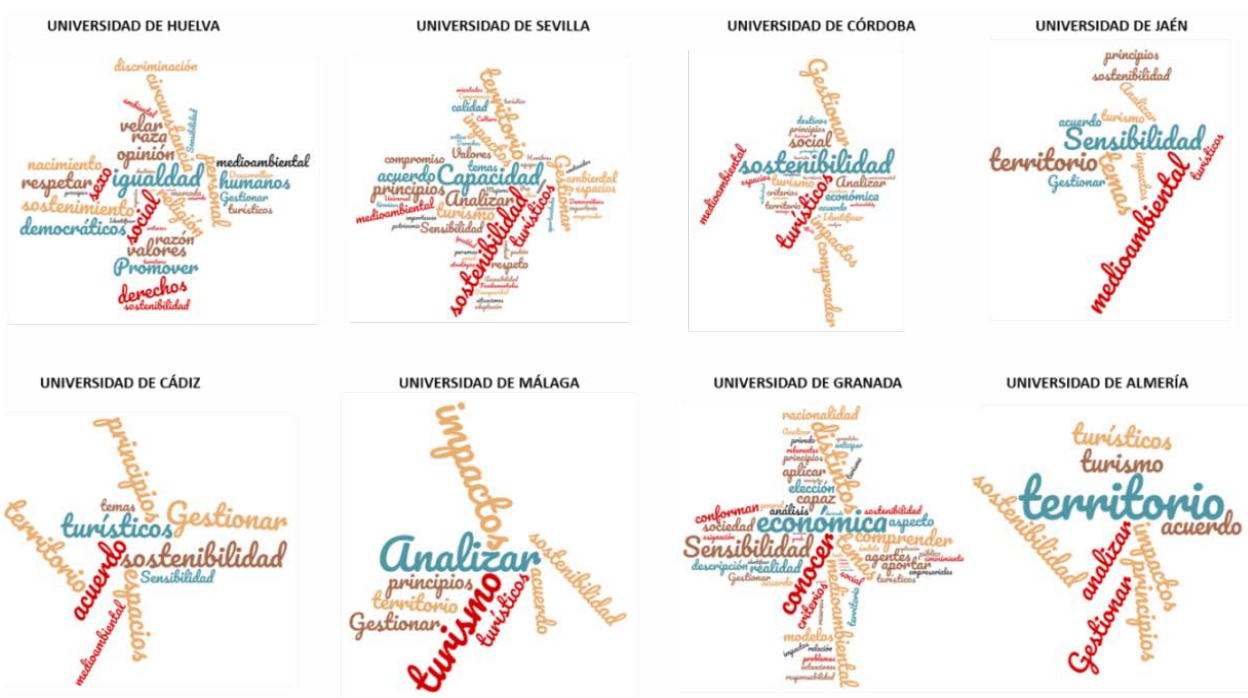

Fuente: Elaboración propia. 


\section{DISCUSIÓN}

El presente trabajo analiza la presencia de contenidos relacionados con la transición ecológica y la emergencia climática en los grados de Turismo andaluces. Diferentes puntos merecen ser discutidos.

\subsection{Sobre la presencia de contenidos y competencias para la TE y la EC: Departa- mentos y materias implicadas}

Los resultados muestran una presencia muy limitada de contenidos en TE y EC: Sólo un 25\% de las asignaturas incluyen en sus programas o en alguno de sus proyectos docentes competencias, contenidos temáticos u objetivos relacionados. Esta afirmación se constata definitivamente cuando analizamos en qué apartados aparecen tales contenidos, ya que una gran proporción de estas asignaturas mencionan éstos sólo en las competencias, pero no las recogen en sus temarios.

Los resultados revelan también un uso mayoritario del concepto de sostenibilidad como eje vertebrador de esos contenidos. De este modo, mientras conceptos como sostenibilidad y los asociados a cada uno de sus pilares (ambiental, económico y social), aparecen repetidamente, existe una ausencia total de nuevos términos relacionados con los nuevos desafíos globales: desde la propia transición ecológica o emergencia climática, a otros conceptos como decrecimiento, resiliencia, cambio climático, ciudadanía global, gobernanza territorial etc.; así como de otros vocablos equivalentes en lo turístico que sí son abordados en el ámbito investigador..En este sentido pueden destacarse, entre otros trabajos, los de Fletcher et al. (2018; 2020); Gascón (2019) y Valdivieso y Moranta (2019) sobre turismo y decrecimiento, Olcina $(2012 ; 2018)$ y Gómez $(2005 ; 2017)$ sobre turismo y cambio climático, Blanco-Romero et al. (2018) y Ramos and Mundet (2021) sobre turismofobia, Fernández et al. $(2015 ; 2017)$ sobre gobernanza territorial y gestión de destinos turísticos o Moira et al. (2017) y De Salvo et al. (2019) sobre slow tourism.

Los resultados muestran además una mayor presencia y repetición de conceptos vinculados al conocimiento de la situación actual, relacionados con el "SABER", mientras que la presencia de términos asociados al "SABER HACER" es mucho menor. Por su parte, la aparición y repetición de los términos relacionados con la intencionalidad ética o el "SABER SER", también es mayor que los vinculados a los contenidos para la acción o "SABER HACER".

A raíz de estos resultados se deriva por tanto la necesidad de revisar los contenidos de los diferentes grados, actualizar los temarios y las estrategias de aprendizaje con la finalidad de incluir los planteamientos, contenidos y las competencias ausentes, así como la de evitar repeticiones o solapamientos innecesarios.

Estos cambios sustanciales "desde arriba" (Libro Blanco, Acuerdos Autonómicos y Planes de Estudio), tan necesarios según Barrón et al. (2010), requieren además de una "impregnación" de estos planteamientos por parte de los docentes, esto es, la asunción de estos contenidos mediante un proceso de enseñanza y aprendizaje como el que luego utilizarían con sus propios alumnos y alumnas (Vilches y Gil, 2012; Sinakou et al., 2019). 
En este sentido, el profesorado se enfrenta a grandes retos para diseñar experiencias de enseñanza-aprendizaje en las que el estudiante pueda entrenar y adquirir dichas competencias, desarrollar un conocimiento para la acción y construir nuevos aprendizajes significativos. Entre ellos, Villar y Díaz (2019) señalaron para el Grado en Turismo de la Universidad de Sevilla el elevado número de alumnos, que no sólo impide la atención personalizada sino que en varias ocasiones complica la incorporación de proyectos de trabajo inter/transdisciplinares entre diferentes áreas y materias, y limita las técnicas docentes a clases magistrales (Villar y Díaz, 2019).

En línea con la interdisciplinariedad del sector turístico y de sus titulaciones, existe una comprobada diversidad en los departamentos que incorporan los contenidos y competencias analizadas. A priori se observa una centralización de los contenidos en ámbitos como la Geografía, Historia, Antropología, Sociología y Humanidades y, seguidamente, entre los departamentos de Economía. El papel que desempeña la Geografía en los grados de Turismo españoles ya ha sido señalado (Martínez y Delgado, 2017; Porcal, 2019; Villar y Díaz, 2019): Su destacada presencia en estos grados, reconocida por el número de asignaturas impartidas, junto a la aproximación interdisciplinar y multiescalar que esta disciplina realiza a su objeto de estudio (relaciones hombre-territorio), la hacen desempeñar un rol estratégico en la impartición de estos contenidos. No es de extrañar por tanto, que a raíz de la conferencia de la ONU sobre el Cambio Climático en diciembre de 2019, la posible inclusión de una asignatura de cambio climático en el currículo de enseñanzas no universitarias haya despertado el interés de geógrafos, que se han ofrecido para impartirla en la escuela y en la enseñanza educativa obligatoria (Colegio de Geógrafos de España y Asociación Española de Geografía, 2019).

Los Idiomas aglutinan por lo general el $22,4 \%$ de las asignaturas que se imparten en los grados de Turismo andaluces. La consideración de que una mayor presencia de idiomas puede frenar la inclusión de contenidos sobre la temática es una posibilidad, pero también en estas asignaturas podría ser más fácil incorporar contenidos -o competenciasrelacionados, aunque no se traten de manera profunda. De hecho, se podría incentivar la inclusión de contenidos (textos, videos, prácticas) sobre la emergencia global o climática también en las materias instrumentales (estadística sobre datos medioambientales en vez de empresariales, visores del territorio, SIG...).

\subsection{Sobre la sostenibilidad como eje central de las enseñanzas universitarias}

Como ya se ha comentado, los resultados arrojan un uso mayoritario del concepto de sostenibilidad como eje vertebrador de los contenidos analizados. Los esfuerzos por la sostenibilización curricular en la Universidad Española se remontan a 2002, a partir de diversas reuniones de trabajo de la CRUE que se materializan en unas directrices tres años más tarde (véase CRUE, 2005). Sin embargo, se han venido detectando dificultades de implantación y acciones muy puntuales (Barrón et al., 2010). Bajo este marco, y también en línea con los Objetivos de Desarrollo Sostenible y la Agenda 2030 (donde la sostenibilidad se erige como fundamento del propósito educativo), emergen en la última década investigaciones que desarrollan ideas y metodologías de aprendizaje innovadoras al respecto: "paradigma de la complejidad" (Bonil et al., 2010), la responsabilidad social 
(De la Rosa et al., 2019), espacios de experiencias en torno a la Educación Ambiental (Navarrete et al., 2019), entre otras.

No obstante, tal y como ya se ha comentado, el significado y el rigor del término sostenibilidad ha sido objeto de debate en los últimos años (Aznar et al., 2011). Como alternativa a la línea científica más institucional, otros académicos han empezado a plantear el uso de otros términos y, por ende, otros paradigmas como núcleo del modelo didáctico. Entre ellos destacan los trabajos de García et al. (2019a y 2019b), que apuntan a la noción de decrecimiento como eje de unos contenidos y unas metodologías basadas en la investigación y el pensamiento complejo. Aunque entendemos que su inclusión es importante en el currículo turístico, su uso como línea principal es complicado en un proceso educativo donde participan departamentos, líneas de investigación y sensibilidades dispares.

Estos planteamientos requerirían de cambios globales en los estudios de Turismo, como por ejemplo (siguiendo a Barón et al., 2010): la adopción de visiones complejas y dinámicas de la realidad turística (ecosistema turístico, inteligencia territorial...), la interacción con organizaciones sociales y administraciones, la salida de campo o el aterrizaje definitivo de la flexibilidad curricular (por ejemplo con proyectos entre materias). En este sentido, y siguiendo una de las estrategias de la CRUE, podrían identificarse ejes temáticos transversales que trasciendan a las estructuras de curso o asignatura. La propia CRUE (2005) resumía el objetivo de la educación (universitaria) en formar personas participativas y pro-activas que sean capaces de tomar decisiones responsables, tomando conciencia de los desafíos que plantea la globalización. Pero para que esos futuros profesionales del turismo logren una incidencia económica y política debe haber una incidencia curricular que, veinte años después y a tenor de nuestros resultados, no se ha producido. Tal y como señalan Caballer et al. (2019), el alumnado de Turismo otorga poca importancia a que la titulación le permita desarrollar una conducta más emprendedora, dinámica y creativa: la percepción de la precariedad laboral en el sector influye en su menor motivación por la carrera y posiblemente en sus aspiraciones profesionales ¿podrían ayudar las nuevas nociones vinculadas a la globalidad y sus metodologías de aprendizaje? Nosotros entendemos que pueden ayudar a empoderar al alumnado de turismo de cara a su futuro, incidiendo en su responsabilidad y labor como futuros profesionales del sector.

\subsection{Sobre las limitaciones y las perspectivas de investigación}

El análisis realizado posee una serie de limitaciones que entendemos como perspectivas de investigación a corto y medio plazo. La primera de ellas es que la ausencia de contenidos y competencias de la TE y EC en los programas y proyectos docentes no quiere decir que estos no se impartan. Efectivamente, con relación a los contenidos, aunque éstos vienen hasta cierto punto establecidos en el Plan de Estudios y en los programas docentes, que tienden a ser más neutros y estar acordados por el conjunto de profesores del Departamento, con opiniones o sensibilidades dispares en ocasiones, el profesor tiene cierto margen de maniobra en el proyecto docente (Villar y Díaz, 2019). No obstante, al no aparecer, su importancia se diluye. En segundo lugar, no se han estudiado las líneas y los títulos de Trabajos Fin de Grado, para comprobar hasta qué punto estos proyectos, 
por su carácter integrador, mitigan la limitada presencia de los contenidos analizados en el resto de materias. En tercer lugar, el análisis realizado podría sumarse a otros similares pero centrados en las otras familias conceptuales del turismo, sobre todo, la del ámbito corporativo (crecimiento económico, beneficio empresarial...). Finalmente, concebimos que el estudio debiera ampliarse al conjunto de los Grados de Turismo en España, sin menoscabar la posibilidad de sondear algunos centros internacionales de referencia.

\section{CONCLUSIONES}

Los nuevos desafíos globales vinculados a la emergencia climática y la transición ecológica exigen de profesionales que conozcan y comprendan la realidad y sus problemáticas, que desarrollen un pensamiento complejo para gestionarlas y para buscar alternativas y/o estrategias de adaptación a diversas escalas. El desarrollo de este pensamiento complejo y "glocal" requiere además de una evolución desde enfoques uni/multidisciplinares a perspectivas inter/transdisciplinares. Conocer si esta transición se está llevando a cabo, si estos conocimientos se están impartiendo, o si las competencias necesarias se están entrenando en los grados universitarios (responsables de formar a gran parte de estos profesionales o ciudadanos) resulta por tanto fundamental.

Las enseñanzas de turismo son un "laboratorio" ideal para valorar esa transición, porque la dirección empresarial de su currículo se encuentra tamizada por el sentido del territorio, la globalización (económica, social, sanitaria...), el desarrollo sostenible o la responsabilidad social, entre otros.

Este trabajo analiza la presencia de contenidos y competencias relacionadas con la transición ecológica y la emergencia climática en las enseñanzas universitarias de Turismo en Andalucía. Los resultados muestran una representación muy limitada, así como la ausencia total de conceptos emergentes sobre los nuevos desafíos globales y las nuevas pautas o alternativas de desarrollo turístico. Sólo un $25 \%$ de las asignaturas presenta contenidos relacionados en sus proyectos o programas docentes. Estos escasos contenidos giran únicamente en torno al concepto de sostenibilidad, en línea a la sostenibilización curricular que desde 2002 trata de aplicar la Universidad Española, pero se olvida de otros como el cambio climático, el decrecimiento, la banalización cultural o la gobernanza territorial; todos ellos, con sólidas referencias en la investigación y fuertes implicaciones en el turismo. Se observa además un encapsulamiento de los contenidos en "píldoras" de racionalidad teórica (SABER) y ética (SABER SER Y VALORAR), frente a "tratamientos" completos que incluyan competencias para la acción (SABER HACER). A raíz de estos resultados se deriva por tanto la necesidad de realizar una profunda revisión de planteamientos, competencias y contenidos, desde los planes de estudio (desde arriba) a los programas y proyectos docentes (desde abajo).

El turismo es una de las grandes industrias planetarias, en generación de capitales, empleos y rentas, pero también en transformaciones territoriales y huella ecológica. La incidencia política (discursos sólidos, leyes, planes,) y económica (estándares medioambientales, responsabilidad social...) de una nueva cultura del desarrollo (turístico) y un pensamiento complejo y glocal requiere una mayor incidencia académica de los conteni- 
dos aludidos, de una parte, y un fortalecimiento del conocimiento para la acción (SABER HACER) a través de nuevos aprendizajes significativos, de otra.

Entendemos que ambos procesos, el aterrizaje de los referidos planteamientos teóricos y el desarrollo de nuevas metodologías de aprendizaje, pueden empoderar al alumnado (y futuros profesionales) de turismo para "adueñarse" de su futuro, ayudarle a implementar visiones totalizadoras que conduzcan hacia empresas y administraciones socialmente responsables, ambientalmente respetuosas y económicamente rentables.

\section{AGRADECIMIENTOS}

Este articulo forma parte de las investigaciones desarrolladas en el Programa Nacional de Proyectos de Investigación Fundamental titulado "Inteligencia territorial Vs. crecimiento turístico. La planificación y gestión de destinos ante el nuevo ciclo expansivo inmobiliario" (Ref. PGC2018-095992-B-I00), financiado por el Ministerio de Ciencia, Innovación y Universidades del Gobierno de España.

Declaración responsable: Los autores declaran que no existe ningún conflicto de interés en relación a la publicación de este artículo. Las tareas asociadas al trabajo se han distribuido de manera equitativa y cada autor ha participado en todos los apartados del artículo trabajando especialmente el diseño general, coordinación y contextualización Pilar Díaz, el tratamiento de datos y elaboración de figuras Daniel Becerra, y la revisión del texto y conclusiones Arsenio Villar.

\section{BIBLIOGRAFÍA}

ANECA (2004): Libro Blanco del Título de Grado en Turismo.

ALBAREDA TIANA, S., FERNÁNDEZ MORILLA, M., MALLARACH CARRERA, J.M. y VIDAL RAMÈNTOL, S. (2017): «Barreras para la sostenibilidad integral en la Universidad», Revista Iberoamericana de Educación, n ${ }^{\circ}$ 73, pp. 253-272.

AZNAR, P. y ULL, A. (2009): «La formación de competencias básicas para el desarrollo sostenible: el papel de la Universidad», Revista de Educación, no 1, pp. 219-227.

AZNAR, P., MARTINEZ-AGUT, M.P., PALACIOS, B., PIÑERO A. y ULL, A. (2011): «Introducing sustainability in to university curricula: an indicator and baseline survey of the views of university teachers at the University of Valencia», Environmental Education Research, vol. 17 (2), pp. 145-166.

AZNAR MINGUET, P., ULL, M.A., PIÑERO, A. y MARTÍNEZ-AGUT, M.P. (2014):«La sostenibilidad en la formación universitaria: desafíos y oportunidades», Educación $X X 1$, vol. 17, (1), pp. 133-158.

BARRÓN, Á., FERRER, D. y NAVARRETE, A. (2010): «Sostenibilización curricular en las universidades españolas ¿ha llegado la hora de actuar?», Revista Eureka, $\mathrm{n}^{\circ} 7$, pp. 388-399.

BARTH, M.; GODEMANN, J.; RIECKMANN, M.; STOLTENBERG, U. (2007): «Developing Key Competencies for Sustainable Development in Higher Education», International Journal of Sustainability in Higher Education, vol. 8 (4), pp. 416-430. 
BLANCO-ROMERO, A., BLÁZQUEZ-SALOM, M. y MORELL, M. (2018): «Turismofobia como arma arrojadiza», Revista Ábaco, n ${ }^{\circ}$ 98, pp. 55-64.

BONIL, J., JUNYENT, M. y PUJOL, R.M. (2010): «Educación para la sostenibilidad desde la perspectiva de la complejidad», Revista Eureka sobre Enseñanza y Divulgación de las Ciencias, $\mathrm{n}^{\circ} 7$ ( $\mathrm{N}^{\circ}$ Extraordinario), pp. 198-215.

BYBEE, R. (1991): «Planet Earth in Crisis: How Should Science Educators Respond?», The American Biology Teacher, vol. 53 (3), pp. 146-153.

CABALLER-TARAZONA, M., CUÑAT GIMÉNEZ, R.J., MARTÍNEZ VERDÚ, R. y PARDO-GARCÍA, C. (2019): «¿Por qué eligen los estudiantes universitarios las titulaciones de turismo? Análisis de los factores de interés y expectativas de empleo para el alumnado de la Universitat de València», Cuadernos de Turismo, no 44, pp. 43-65.

CEBRIÁN, G., JUNYENT, M. y MULÀ, I. (2020): «Competencies in Education for Sustainable Development: Emerging Teaching and Research Developments», Sustainability, vol. 12 (1), 579.

COLEGIO DE GEÓGRAFOS DE ESPAÑA y ASOCIACIÓN ESPAÑOLA DE GEOGRAFÍA (2019): Declaración del Colegio de Geógrafos-AGE sobre la asignatura cambio climático.

COLOM, A. (2000): Desarrollo sostenible y educación para el desarrollo. Barcelona, Octaedro.

COMISIÓN MUNDIAL DEL MEDIO AMBIENTE Y DEL DESARROLLO (1992): Cumbre de la Tierra. The United Nations Conference on Environment and Development.

CRUE (2005): Directrices para la introducción de la Sostenibilidad en el Curriculum. Revisión aprobada en sesión Plenaria en la Universidad de Zaragoza (17/06/2011) y ampliada en la Universidad de Valencia (9/3/2012).

CRUE (2012): Directrices para la introducción de la Sostenibilidad en el Currículum. Revisión del documento aprobado por la Asamblea General, en 2005.

DA CRUZ, G. (2009): «Cambio climático y turismo: posibles consecuencias en los destinos turísticos de Bahía - Brasil», Estudios y Perspectivas en Turismo, vol. 18 (4), pp. 476-489.

DE LA ROSA, D., GIMÉNEZ, P. y MALDONADO, C. (2019): «Educación para el desarrollo sostenible: el papel de la universidad en la Agenda 2030», Prisma Social, $\mathrm{n}^{\circ} 25$, pp. 179-202.

DE SALVO, P., CALZATI, V. y SOGLIA. S. (2019): «Value for Time: Slowness, a Positive Way of Performing Tourism: Best Practices», en Best Practices in Hospitality and Tourism Marketing and Management: A Quality of Life Perspective. Cham, Springer, pp. 315-336.

DIAMOND, J. (2006): Colapso: por qué unas sociedades perduran y otras desaparecen. Barcelona, Debate.

DÍAZ-CUEVAS, M.P. y BECERRA-FERNÁNDEZ, D. (2020): «Una propuesta didáctica interdisciplinar para la incorporación de la sostenibilidad en el ámbito universitario: Aproximación a los impactos de la actividad turística en la Universidad de Sevilla», en Analizando el fenómeno docente del futuro. Madrid, Ediciones Pirámide, pp. 129-140. 
DUARTE, C. (2006): Cambio global. Impacto de la actividad humana sobre el sistema Tierra. Madrid, CSIC.

FARIOLLY, F., MAYET, M., y DEL GOBBO, G. (2017): «Learning for an unpredictable future: what competences for educators», Enseñanza de las ciencias. Revista de investigación y experiencias didácticas, $\mathrm{n}^{\circ}$ Extraordinario, pp. 4.961-4.966.

FERNÁNDEZ, A., MERCADO, I., VILLAR, A. y BASCARÁN, V. (2015): «Gobernanza territorial y gestión de espacios turísticos en contextos de fuerte presión inmobiliaria. Análisis de buenas prácticas locales en la costa de Cádiz (España)», Revista de Geografía Norte Grande, $\mathrm{n}^{\circ}$ 60, pp.173-194.

FERNÁNDEZ, A., FORONDA, C., GALINDO, L. y GARCÍA, A. (2017): «Developing a system of territorial governance indicators for tourism destinations», Journal of Sustainable Tourism, vol. 25 (9), pp. 1.275-1.305.

FLETCHER, R., BLANCO-ROMERO, A., BLÁZQUEZ-SALOM, M. y MURRAY, I. (2018): Tourism and Degrowth: Impossibility Theorem or Path to Post-Capitalism?, Entitle collective, 8/4/2018.

FLETCHER, R., MURRAY, I., BLANCO ROMERO, A. y BLÁZQUEZ-SALOM, M. (2020): Tourism and Degrowth: Towards a Truly Sustainable Tourism. Routledge.

GARCÍA DÍAZ, E. (2004a): Educación Ambiental, Constructivismo y Complejidad: una propuesta integradora. Sevilla, Díada.

GARCÍA DÍAZ, E. (2004b): «Los contenidos de la educación ambiental: una reflexión desde la perspectiva de la complejidad», Investigación en la Escuela, ${ }^{\circ}$ 53, pp. 31-52.

GARCÍA DÍAZ, E. y RODRÍGUEZ MARÍN, F. (2018-2019): Educar en y para el decrecimiento (documento que recoge diversos materiales trabajados). Sevilla, Universidad de Sevilla.

GARCÍA DÍAZ, J.E., FERNÁNDEZ ARROYO, J., RODRÍGUEZ MARÍN, F., y PUIG GUTIÉRREZ, M. (2019a): «Más allá de la sostenibilidad: por una educación ambiental que incremente la resiliencia de la población ante el decrecimiento/colapso», Revista de Educación Ambiental y Sostenibilidad, vol. 1 (1), p. 1.101.

GARCÍA DÍAZ, J.E., RODRÍGUEZ MARÍN, F., FERNÁNDEZ ARROYO, J. y PUIG GUTIÉRREZ, M. (2019b): «La educación científica ante el reto del decrecimiento», Alambique: Didáctica de las ciencias experimentales, $\mathrm{n}^{\circ}$ 95, pp. 47-52.

GARCÍA-PÉREZ, F.F. (2016): «Educar en la escuela para afrontar los problemas del mundo», en Más allá de lo imposible. La dimensión política de los derechos humanos en el siglo XXI. Tafalla, Ed. Txalaparta, pp. 145-171.

GARRITZ, A., VILCHES, A. y GIL PÉREZ, D. (2014): «Una revolución científica a la que Educación Química quiere contribuir», Educación Química, vol. 25 (3), pp. 290-291.

GASCÓN, J. (2019): «Tourism as a right: a "frivolousclaim" againstdegrowth?», Journal of Sustainable Tourism, vol. 27 (12), pp. 1825-1838.

GÓMEZ, M.B. (2005): «Weather, climate and tourism a geographical perspective», Annals of Tourism Research, vol. 32 (3), pp. 571-591.

GÓMEZ, M.B. (2017): «Retos del turismo español ante el cambio climático», Investigaciones Geográficas, nº 67 , pp. 31-47. 
HERAS, F. (2016): «Education in times of climate change: facilitating learning to build a culture of climate-protection», Mètode. Science Studies Journal: Annual Review, vol. 6, pp. 64-71.

LAMBRECHTS, W., VERHULST, E. y RYMENAMS, S. (2017): «Professional development of sustainability competences in higher education: The role of empowerment», International Journal of Sustainability in Higher Education, vol. 18 (5): pp. 697-714.

LAWN, M. (2011): «Standardizing the European Education Policy Space», European Educational Research Journal, vol. 10 (2), pp. 259-272.

MARTÍNEZ FERNÁNDEZ, L.C. y DELGADO URRECHO, J.M. (2017): «La Geografía en las enseñanzas universitarias de Grado en España: docencia y planes de estudios», Investigaciones Geográficas, $\mathrm{n}^{\circ}$ 67, pp. 61-79.

MEADOWS, D.H., MEADOWS, D.L., RANDERS, J. y BEHRENS III, W.W. (1972): Limits to Growth. Nueva York, Universe Books.

MINDT, L. y RIECKMANN, M. (2017): «Desarrollo de las competencias para el emprendimiento orientado a la sostenibilidad en la educación superior: una revisión bibliográfica de los métodos de enseñanza y aprendizaje», Teoría de la Educación. Revista Interuniversitaria, vol. 29 (1), pp. 129-159.

MOIRA, P., MYLONOPOULOS, D. y KONDOUDAKI, A. (2017): «The Application of Slow Movement to Tourism: Is Slow Tourism a New Paradigm?», Journal of Tourism and Leisure Studies, vol. 2 (2), pp. 1-10.

MORENO, A. (2010): «Mediterranean Tourism and Climate (Change): A Survey-Based Study», Tourism and Hospitality Planning \& Development, vol. 7 (3), pp. 253-265.

MURGA-MENOYO, M.A. y NOVO, M. (2017): «Sostenibilidad, Desarrollo «Glocal» y ciudadanía planetaria. Referentes de una pedagogía para el desarrollo sostenible», Teoría de la Educación. Revista interuniversitaria, vol. 29 (1), pp. 55-78.

NAVARRETE, A., AZCÁRATE, M.D.P., JIMÉNEZ-FONTANA, R., CARDEÑOSO, J.M. y GARCÍA-GONZÁLEZ, E. (2019): «Publicar sobre Educación Ambiental y Educación para la Sostenibilidad, ¿dónde?», Revista de Educación Ambiental y Sostenibilidad, vol. 1 (1), p. 1.303.

OLCINA, J. (2012): «Turismo y cambio climático: una actividad vulnerable que debe adaptarse», Investigaciones Turísticas, $\mathrm{n}^{\circ} 4$, pp. 1-34.

OLCINA, J. (2018): «¿Puede el cambio climático alterar la actividad turística en nuestro país?», Abaco: Revista de cultura y ciencias sociales, ${ }^{\circ}$ 98, pp. 97-104.

ONU (2012): Learning for the future. Competences in Education for Sustainable Development.

ONU (2019): Perspectivas del medio ambiente mundial.

PROGRAMA DE LAS NACIONES UNIDAS PARA EL DESARROLLO - PNUD (2016): Objetivos de desarrollo sostenible.

PORCAL, M.C. (2019): Informe sobre la vocalía de enseñanzas universitarias. Madrid, Asociación Española de Geografía.

RAMOS, S.P. y MUNDET, L. (2021): «Tourism-phobia in Barcelona: dismantling discursive strategies and power games in the construction of a sustainable tourist city», Journal of Tourism and Cultural Change, vol. 19 (1), pp. 113-131. 
REAL DECRETO 1393/2007, DE 29 DE OCTUBRE, POR EL QUE SE ESTABLECE LA ORDENACIÓN DE LAS ENSEÑANZAS UNIVERSITARIAS OFICIALES. Ministerio de Educación y Ciencia «BOE» núm. 260, de 30 de octubre de 2007 Referencia: BOE-A-2007-18770.

SIDDIQUI, S. e IMRAN, M. (2018): «Impact of Climate Change on Tourism», en Impact of Climate Change on Tourism. IGI Global, pp. 68-83.

SINAKOU, E., BOEVE-DE PAUW, J. y VAN PETEGEM, P. (2019): «Exploring the concept of sustainable development within education for sustainable development: implications for ESD research and practice», Environ Dev Sustain, vol. 21 (1), pp. 1-10.

SMITH, K. (1990): «Tourism and climate change», Land Use Policy, vol. 7 (2), pp. 176180.

STERLING, S. (2005): «Higher education, sustainability, and the role of systemic learning", en Higher education and the challenge of sustainability: Problematics, promise and practice. Dordrecht, Kluwer Academic Press, pp. 49-70.

VALDIVIELSO, J. y MORANTA, J. (2019): «The social construction of the tourism de growth discourse in the Balearic Islands», Journal of Sustainable Tourism, vol. 27 (12), pp. 1.876-1.892.

VILCHES, A. y GIL, D. (2012): «La Educación para la Sostenibilidad en la Universidad: el reto de la formación del profesorado», Profesorado: Revista de Currículum y Formación de Profesorado, vol. 16 (2), pp. 25-43.

VILCHES, A. y GIL PÉREZ, D. (2015): «Ciencia de la Sostenibilidad: ¿Una nueva disciplina o un nuevo enfoque para todas las disciplinas? », Revista Iberoamericana de Educación, vol. 69 (1), pp. 39-60.

VILLAR, A. y DÍAZ, P. (2019): «La presencia de la geografía en las enseñanzas universitarias. Retos docentes en el grado de Turismo», en La reconfiguración del medio rural en la sociedad de la información. Nuevos desafíos en la educación geográfica. Quiroga (Lugo), Editorial Andavira, pp. 21-34.

ZÚÑIGA, A., LEINTON, R. y NARANJO, J.A. (2014): «Del sistema educativo tradicional hacia la formación por competencias: Una mirada a los procesos de enseñanza aprendizaje de las ciencias en la educación secundaria de Mendoza Argentina y San José de Costa Rica», Revista Eureka sobre Enseñanza y Divulgación de las Ciencias, vol.11 (2), pp. 145-159. 